*This manuscript has been authored by UT-Battelle, LLC under Contract No. DE-AC05-00OR22725 with the U.S. Department of Energy. The United States Government retains and the publisher, by accepting the article for publication, acknowledges that the United States Government retains a non-exclusive, paid-up, irrevocable, world-wide license to publish or reproduce the published form of this manuscript, or allow others to do so, for United States Government purposes. The Department of Energy will provide public access to these results of federally sponsored research in accordance with the DOE Public Access Plan (http://energy.gov/downloads/doe-public-access-plan).

\title{
Cladding burst behavior of Fe-based alloys under LOCA*
}

\author{
Caleb Massey ${ }^{\mathrm{a}, \mathrm{b}}$, Kurt Terrani ${ }^{\mathrm{a}, 1}$, Sebastien Dryepondt ${ }^{\mathrm{a}}$, Bruce Pint $^{\mathrm{a}}$ \\ ${ }^{a}$ Oak Ridge National Laboratory, Oak Ridge, TN 37831 \\ ${ }^{\mathrm{b}}$ Department of Mechanical and Nuclear Engineering, Virginia Commonwealth University, Richmond, VA 23228 \\ ${ }^{1}$ Corresponding author: terranika@ornl.gov, 865-576-0264
}

\begin{abstract}
Burst behavior of austenitic and ferritic Fe-based alloy tubes has been examined under a simulated large break loss of coolant accident. Specifically, type 304 stainless steel (304SS) and oxidation resistant FeCrAl tubes were studied alongside Zircaloy-2 and Zircaloy-4 that are considered reference fuel cladding materials. Following the burst test, characterization of the cladding materials was carried out to gain insights regarding the integral burst behavior. Given the widespread availability of a comprehensive set of thermo-mechanical data at elevated temperatures for 304SS, a modeling framework was implemented to simulate the various processes that affect burst behavior in this $\mathrm{Fe}$ based alloy. The most important conclusion is that cladding ballooning due to creep is negligible for Fe-based alloys. Thus, unlike Zr-based alloys, cladding cross-sectional area remains largely unchanged up to the point of burst. Therefore, for a given rod internal pressure, the temperature onset of burst in Fe-based alloys appears to be simply a function of the alloy's ultimate tensile strength, particularly at high rod internal pressures.
\end{abstract}

\section{Introduction}

Given the strengthened focus on development of accident tolerant nuclear fuel cladding materials after the beyond design basis accidents at Fukushima Daiichi in March 2011, a reexamination of Fe-based alloys for this purpose was proposed [1]. Specifically, such accident tolerant materials are expected to exhibit at least $100 \times$ slower oxidation rates at $\geq 1200^{\circ} \mathrm{C}$ when compared to $\mathrm{Zr}$ based alloys. The rational is discussed in detail in a number of recent publications [1-4], though briefly, it is intended to reduce the extent of heat (due to the exothermic oxidation reaction) and 
hydrogen gas production (an inevitable byproduct of oxidation by $\mathrm{H}_{2} \mathrm{O}$ ) inside the core and therefore enhance safety margins during severe accidents. Although oxidation rate is considered as the key factor for enhanced accident tolerance, many other aspects of the integral fuel rod behavior, including its thermo-mechanical response, melt, and relocation are also important and need to be considered. To this end, the focus of this paper has been placed on burst behavior of Fe-based alloys as light water reactor (LWR) fuel cladding and compared to the well-known $\mathrm{Zr}$ based alloys.

The burst behavior of Fe-based alloys was examined under test conditions corresponding to a large-break loss of coolant accident (LB-LOCA) sequence, that is a postulated design basis (DB) accident for light water reactors (LWR) systems as described in the code of federal regulations 10CFR $\$ 50.46$. Under LB-LOCA conditions, which is simulated as a guillotine-type break in one of the primary loop cold legs of the reactor, the water within the core begins to flash to steam and exit into containment from the reactor core, leaving the fuel rods without sufficient cooling. As the water flashes to steam, a transition occurs from nucleate boiling to film boiling, which severely hinders heat transfer and prevents the cladding from expelling the fuel's decay heat and stored internal energy. At the same time during this high-temperature transient, the pressure within the core decreases until it reaches equilibrium with the containment pressure ( 0.2 $\mathrm{MPa}$ ) causing an increasing differential pressure between the sealed cladding tubes and the now depressurized core. The high temperature creep of cladding (that results in ballooning and reduction in cladding cross-sectional area) coupled with the high-temperature oxidizing environment (that consumes the load-bearing metal), steadily increases the hoop stress felt by the cladding until burst occurs.

Two classes of Fe-based alloys have been investigated in this study: austenitic 304 stainless steel that was occasionally used as fuel cladding in LWRs prior to the 1980s [5, 6] and alumina forming ferritic FeCrAl alloys that are currently being developed as LWR accident tolerant fuel (ATF) cladding materials [1]. While 304SS is a widespread commercial alloy and was procured as such, the FeCrAl alloys were produced at ORNL in rod form and the claddings that were burst tested in this study were from very small commercial tube production trials and represent the first generation model FeCrAl alloys intended for the cladding application and therefore do not benefit from any systematic microstructural control and strengthening strategies that were utilized for the later generations. Details of multi-generation $\mathrm{FeCrAl}$ alloy development for cladding application are summarized elsewhere [7]. However, burst test results from these earlystage alloys should provide useful information for the ATF development activities.

In addition to the tube burst tests, two $800^{\circ} \mathrm{C}$ creep tests were carried out on small dogbone tensile specimens of second generation FeCrAl alloys. This limited data when compared with 304SS and Zr-based alloys allow qualitative interpretations with respect to burst behavior. 
Zircaloy burst tests were also carried out as benchmarks against the vast set of literature data available [8-11]. Initially, a review of cladding burst process in Zr-based alloys is provided for background. Following that section, methodology and results of the burst tests and simplified models to understand those experimental results are detailed. Finally, a discussion on important phenomenological differences between Fe- and Zr-based alloys from a cladding burst perspective is provided.

\section{Review of the burst process in $\mathrm{Zr}$-based alloys}

Burst behavior of Zr-based alloys under LOCA scenarios has received extensive attention over the decades since their first utilization as nuclear fuel cladding in the 1950s [8-11]. Two main phenomena govern burst behavior of the Zr-based cladding: creep [12] and oxidation [13]. Cladding creep during the transient temperature excursion results in cladding ballooning given the pressure differential. While ballooning affects heat transfer characteristics of the structure, it mainly results in thinning the cladding cross-section and therefore amplifies the stress at the ballooned region. Cladding oxidation similarly deteriorates the load-bearing capability of the structure by consuming the $\mathrm{Zr}$ metal due to steam oxidation (for irradiated fuel internal oxidation via the urania pellet also needs to be considered [14]).

Creep of Zr-based alloys under a LOCA transient is rather complex since the temperature range includes the $\alpha \rightarrow \beta$ transition $\left(\sim 750-950^{\circ} \mathrm{C}\right)[15,16]$. Therefore separate creep rates, in the distinct $\alpha, \alpha+\beta$, and $\beta$ regions need to be considered for accurate consideration of cladding response. Furthermore, the alloying elements [17], hydrogen and oxygen content in the alloy [18, 19], and the alloy microstructure [20] all affect these creep rates.

Oxidation of the Zr-based alloy cladding has been studied extensively [21, 22]. However, oxidation affects the burst behavior of the Zr-based alloy cladding in a manner more complex than simple metal thickness loss. Oxygen diffuses across the oxide layer into the cladding [23] where it exhibits a very high solubility in $\alpha-\mathrm{Zr}$ [24] and therefore affects the phase transformation kinetics [25] and the mechanical properties of the cladding. A number of state-ofthe-art reviews of cladding burst behavior [26-28] and models [29] are available.

\section{Methodology}

\subsection{Experimental approach}

Cladding burst tests were carried out at ORNL's Severe Accident Test Station, inside the integral LOCA furnace module [30]. Briefly, the setup utilized an $8 \mathrm{~kW}$ infrared furnace to rapidly heat $\left(5^{\circ} \mathrm{C} / \mathrm{s}\right)$ a $30 \mathrm{~cm}$ long, $9.5 \mathrm{~mm}$ diameter, internally pressurized tube. The test configuration consisted of $8.2 \mathrm{~mm}$ diameter, $\sim 15 \mathrm{~mm}$ long zirconia pellets inside a thin-walled tube of the material of interest. The loaded tube was centered inside a quartz furnace tube and had at least three Type-S thermocouples attached to its surface, Fig. 1. The rod was internally pressurized

with He while steam was continuously flowing $(\sim 30 \mathrm{~cm} / \mathrm{s})$ at $0.1 \mathrm{MPa}$ in the quartz tube, i.e. on 
the outside of the thin-walled tube. At the top, away from the heated zone, a miniature pressure transducer was attached to the rod to continuously monitor the pressure inside the rod. Note that the rod was not constrained at the bottom, and was simply hanging from the top. This is important, since any constraint from the bottom could significantly alter the axial stress profile across the tube cross-section and could result in buckling of the tube to exacerbate the burst opening.

The burst test sequence consisted of ramping at $5^{\circ} \mathrm{C} / \mathrm{s}$ from 300 to $1200^{\circ} \mathrm{C}$, holding at $1200^{\circ} \mathrm{C}$ for $3 \mathrm{~min}$, ramp-down to $800^{\circ} \mathrm{C}\left(\sim 5^{\circ} \mathrm{C} / \mathrm{s}\right)$, and finally, quenching with room temperature water. The water entered from the bottom of the quartz tube and rapidly moved upward during the quench phase.

The geometry of the cladding tubes examined in this study is reported in Table 1. The composition of the $1^{\text {st }}$ Gen FeCrAl cladding materials was Fe-13Cr-5Al and Fe-15Cr-4Al (the numbers indicated alloying additions in wt $\%$ ). Both alloys contained $<0.5 \mathrm{wt} \% \mathrm{Y}$. Although this level of variation in alloy composition was present, the effect of composition on performance was deemed negligible since prior mechanical tests on these alloys from $25^{\circ}$ to $600^{\circ} \mathrm{C}$ showed a limited effect of $\mathrm{Cr}$ or $\mathrm{Al}$ content on tensile properties [7, 31].

Table 1. Cladding geometry prior to LOCA test.

\begin{tabular}{|l|c|c|c|}
\hline \multicolumn{1}{|c|}{ Cladding } & ID $[\mathrm{mm}]$ & OD [mm] & Thickness $[\mu \mathrm{m}]$ \\
\hline $\mathrm{Zr}-2$ & 9.75 & 11.16 & 705 \\
\hline $\mathrm{Zr}-4$ & 8.35 & 9.50 & 575 \\
\hline $304 \mathrm{SS}$ & 8.76 & 9.53 & 381 \\
\hline $\mathrm{Fe}-13 \mathrm{Cr}-5 \mathrm{Al}$ & 8.73 & 9.50 & 385 \\
\hline $\mathrm{Fe}-15 \mathrm{Cr}-4 \mathrm{Al}$ & 8.73 & 9.50 & 385 \\
\hline
\end{tabular}



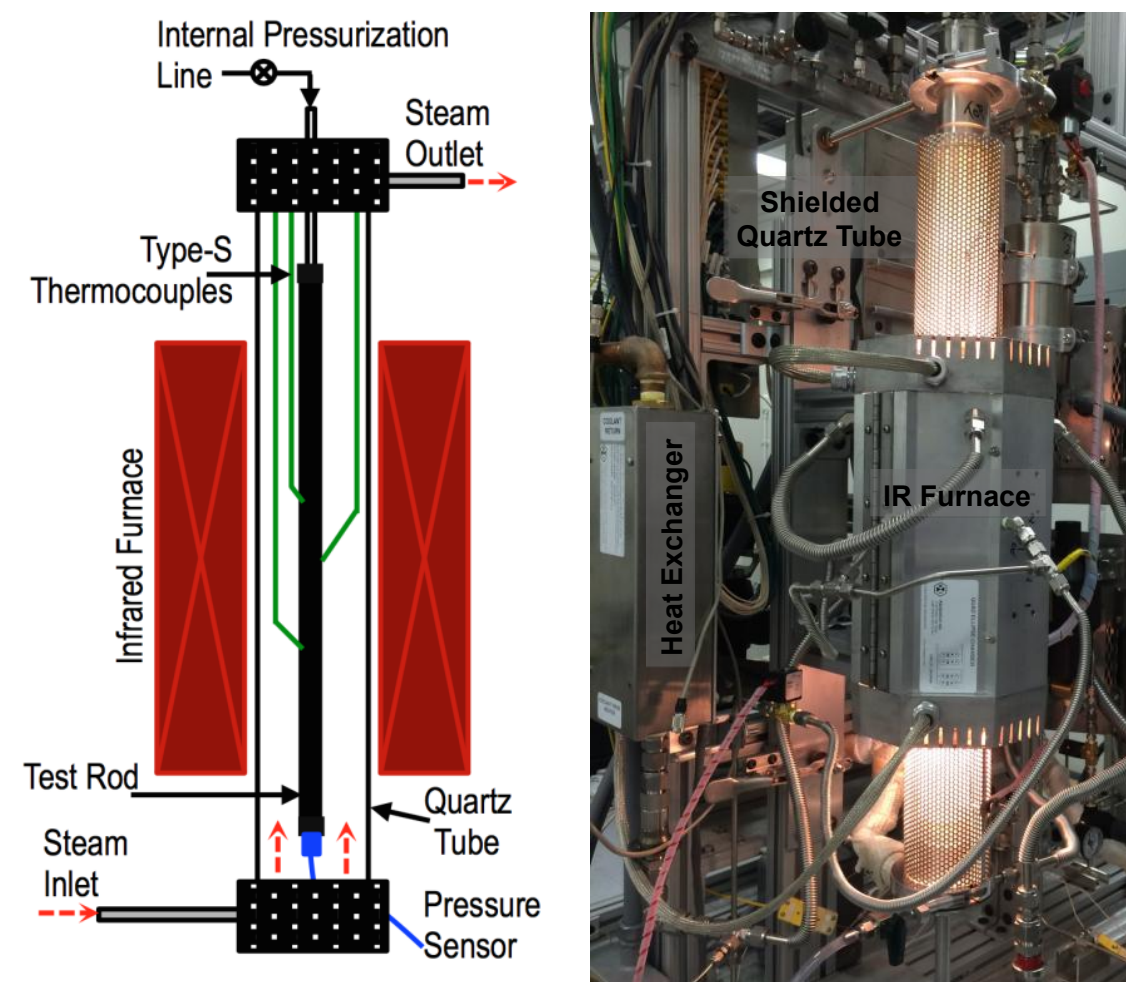

Figure 1. Left: Schematic of the integral LOCA test module at ORNL's Severe Accident Test Station, Right: LOCA module in operation.

After the burst test sequence was completed, the tube diameter was measured using a micrometer $( \pm 5 \mu \mathrm{m})$ at $0^{\circ}$ and $90^{\circ}$ angles across its length. The tubes were then cross-sectioned at the burst location and other locations away from the burst to prepare metallographic specimens for microscopic examination. Scanning electron microscopy (SEM) studies were conducted with a JEOL model 6500 with a field emission gun operating at $15 \mathrm{kV}$ accelerating potential.

\subsection{Modeling approach for Fe-Based cladding}

Burst modeling analysis is necessary to predict the burst temperature, hoop stress, and hoop strain for a given cladding under a LOCA transient. The primary objective of this work, specific to Fe-based alloys, is to couple the thermo-mechanical response of the cladding (including creep) with oxidation to predict the onset of and cladding characteristics at burst. The modeling effort was focused on 304SS since a rich database of high-temperature properties is available for this alloy. Due to the lack of similar data, no analysis was carried out on $1^{\text {st }}$ Gen FeCrAl alloys. However, as will be discussed in the later sections, the phenomena that govern the burst behavior in 304SS can provide insights into the behavior of other Fe-based alloys. As such, this guided understanding can identify the parameters that dominate the behavior of such cladding materials under these conditions. 
The deformation of the cladding was modeled using time-independent elastoplastic data in conjunction with the temperature dependent constitutive equations for creep as studied elsewhere [32-35]. The strength of 304SS decreases with increasing temperature while other mechanical parameters vary [32, 36-39]. To account for the dramatic decreases in the elastic modulus, yield strength, and tensile strength at high temperatures, the mechanical data from Gardner et al. [32] was used to index each property with respect to time and temperature during the simulated transient. For 304SS, the reference values for ultimate tensile strength, yield strength, and elastic modulus at room temperature were $709 \mathrm{MPa}, 398 \mathrm{Mpa}$, and $187 \mathrm{Gpa}$, respectively [33]. Tahami et al. [33] performed uniaxial creep tests on 304SS specimens and have determined the axial creep parameters for this alloy at various elevated temperatures close to those expected under a LOCA scenario. These parameters can then be converted to hoop parameters using Hill's equation [40] in a manner congruent with Rosinger [41].

The true hoop stress $\sigma_{\theta}$ across the tube was determined using the thin tube approximation and was modified to be a function of time [41, 42].

$\sigma_{0}=\Delta p \frac{r}{w}$

and

$\sigma_{\theta}(t)=\sigma_{0}\left(1+\varepsilon_{\theta}(t-d t)\right)^{2}$

where $\Delta p$ is the specified internal rod overpressure, $\varepsilon_{\theta}$ is the true logarithmic hoop (tangential) strain at the given point in time, and $r \& w$ are the initial values of cladding mid-radius and thickness, respectively with respect to time.

For inert conditions, $r$ and $w$ will be independent of time since oxidation is nonexistent. However, for simulation of these LOCA transients in the presence of steam, high-temperature oxidation needs to be considered since it is assumed that the oxide layer offers no load-bearing capability and results in thinning of the metal layer under stress. Brassfield et al. [39] and Ishida et al. [43] have reported the parabolic oxidation rate constant of 304SS in steam. Since the temperature range of their studies is smaller than the temperature range of an applicable LOCA analysis $\left(300-1200^{\circ} \mathrm{C}\right)$, the rate equations have been extrapolated to temperatures below $900^{\circ} \mathrm{C}$. Furthermore, the parameters determined from isothermal oxidation tests are assumed to be applicable for this transient analysis, given the small time step used for the model $(d t<<1 \mathrm{sec})$. The parabolic rate constants is expressed in the Arrhenius form as:

$k=k_{0} * \exp \left(\frac{-Q}{R * T(t)}\right)$ 
where $k_{0}$ is a the pre-exponential constant, $Q$ is the activation energy, and $R$ is the gas constant. The values used from the literature are tabulated in Table 2. For a given temperature and oxide thickness, an equivalent time $(\tau)$ and thus oxidation rate was determined at that time step.

$$
\begin{aligned}
& \tau=\frac{x(t)^{2}}{k} \\
& x(t+d t)=\sqrt{k *(\tau+d t)}
\end{aligned}
$$

The hoop strain at a given point in time is the sum of three components: the elastic strain, the plastic strain, and the creep strain. The elastic and plastic components will vary with temperature and time, but only because the mechanical properties used to calculate each are also temperaturedependent. The sum of the elastic and plastic strains is designated as a rate-independent elastoplastic strain component attained from the stress-strain correlations developed elsewhere [32]. Once the oxide thickness was determined and elasto-plastic strains calculated, $4^{\text {th }}$ order Runge Kutta was used to integrate the creep rate over each time step. The creep rate was assumed to follow the Norton Power Law (NPL) with axial creep parameters given in Table 3 by Tahami et al. [33]. Note that NPL implies steady-state creep and the possibility of faster transient creep mechanisms were ignored. Using Eq. (6), axial parameters were converted to hoop parameters assuming isotropic expansion of the cladding under deformation [41]. Thus, Eq. (6) is a simplification of Hill's Equation using isotropic values for expansion and ballooning. It has been illustrated by Rao et al. that the creep constants used in the strain-rate relation Eq. (7) are dependent on temperature and strain rate $[44,45]$. However, due to a lack of references to the temperature dependency of these strain-hardening constants, the values for constant, $A$, and stress-exponent, $n$, have been assumed constant over the range of temperatures and strain rates calculated in this scenario.

$A_{\theta}=A_{z} *\left(0.866^{n+1}\right)$

$\frac{d \varepsilon_{\theta, \text { creep }}}{d t}=A_{\theta} * \sigma_{\theta}^{n} * \exp \left(-\frac{E}{R * T}\right)=A_{\theta} * \exp \left(-\frac{E}{R * T}\right) * \sigma_{0}^{n} * \exp \left(2 n \varepsilon_{\theta}\right)$

$\varepsilon_{\theta, \text { creep }}(t)=\varepsilon_{\theta, \text { creep }}(t-d t)+d \varepsilon_{\theta, \text { creep }}$

$\varepsilon_{\theta}(t)=\varepsilon_{\text {elasto-plastic }}(t)+\varepsilon_{\theta, \text { creep }}(t)$

The new value for the creep strain was then used to determine new values for total hoop strain and hoop stress, respectively. To determine at what point burst occurs, either the Coffman [46] burst criterion or the ultimate tensile strength can be used as a criterion for burst. Because the curve provided by Coffman only provides burst data for temperatures greater than $1100 \mathrm{~K}$ and the tensile strength data provides a similar and more conservative estimate for burst stress, the ultimate tensile strength data provided by [32] was chosen as the burst criterion for this 
simulation. This is important because a more conservative value for burst stress equates directly to lower calculated values of burst strain and burst temperature. If the hoop stress at any time interval exceeds the burst stress at a given temperature, the rod is considered ruptured and the burst data is recorded as such. A flow diagram for this method is given in Fig. 2.

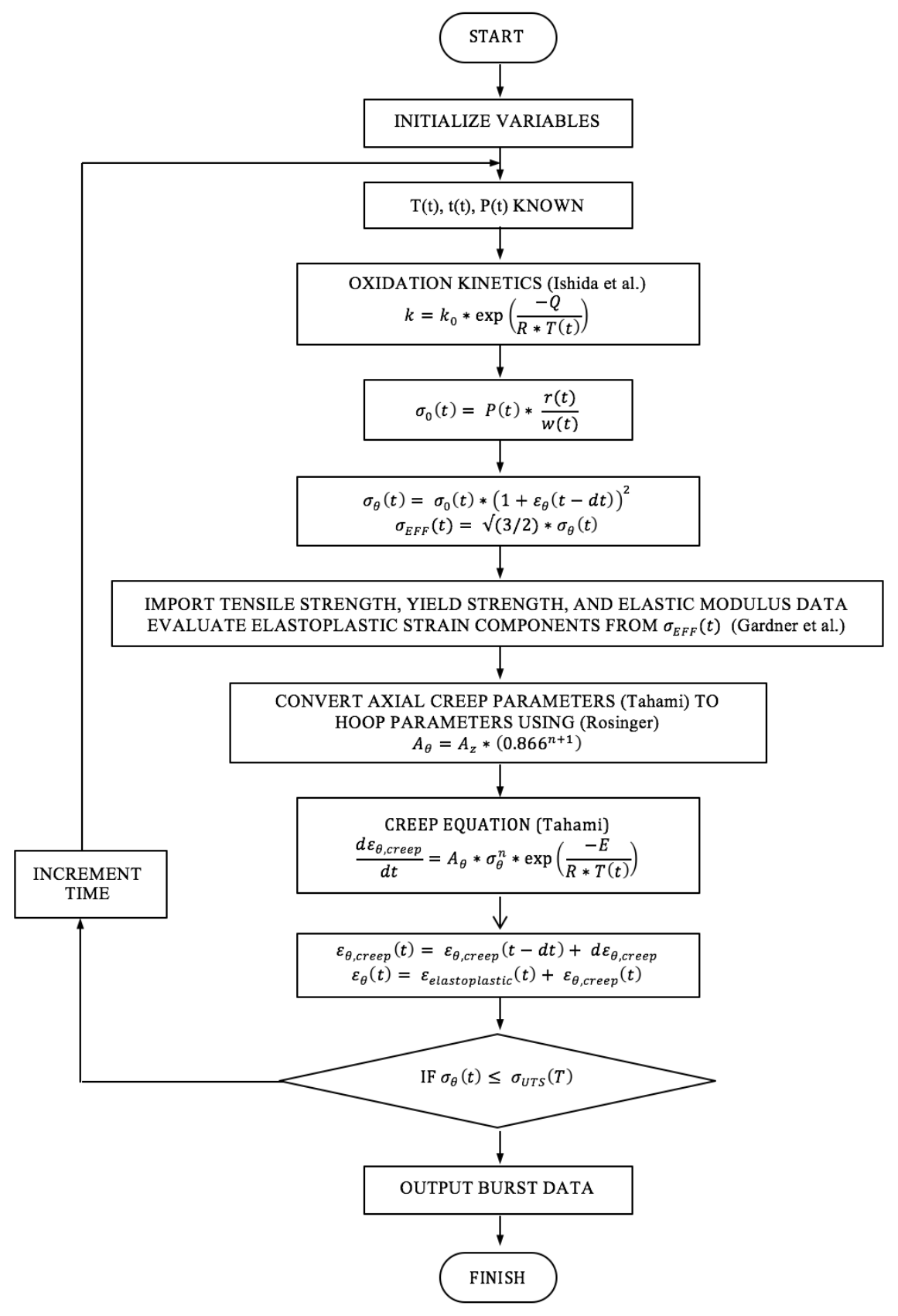

Figure 2. Flow diagram for computational analysis 
Table 2. Steam oxidation kinetic parameters for 304SS from [39, 43]

\begin{tabular}{|c|c|c|c|c|}
\hline \multirow{2}{*}{ Parameter } & \multirow{2}{*}{ Units } & Ishida et al. & Ishida et al. & Brassfield et al. \\
\cline { 3 - 5 } & & $900-1200^{\circ} \mathrm{C}$ & $1200-1350^{\circ} \mathrm{C}$ & $1000-1270^{\circ} \mathrm{C}$ \\
\hline $\mathrm{k}_{0}$ & {$\left[\mathrm{~g} / \mathrm{cm}^{2} \mathrm{~s}^{1 / 2}\right]$} & $8.57^{*}$ & $4.3 \times 10^{4 *}$ & $1.55 \times 10^{3}$ \\
\hline $\mathrm{Q}$ & {$[\mathrm{kJ} / \mathrm{mol}]$} & 129.2 & 234.7 & 176.5 \\
\hline
\end{tabular}

*Oxygen density of $1.6 \mathrm{~g} / \mathrm{cm}^{3}$ is assumed in the resulting oxide to convert these kinetic parameters from ref [43].

Table 3. Creep Constitutive Parameters for 304L SS from [4]

\begin{tabular}{|l|l|l|}
\hline Parameter & Units & Value \\
\hline$A_{z}$ & {$\left[\mathrm{MPa}^{-n} \mathrm{~s}^{-1}\right]$} & $1.67 \times 10^{-8}$ \\
\hline $\mathrm{A}_{\theta}$ & {$\left[\mathrm{MPa}^{-\mathrm{n}} \mathrm{s}^{-1}\right]$} & $6.34 \times 10^{-9}$ \\
\hline $\mathrm{n}$ & $\mathrm{N} / \mathrm{A}$ & 5.7278 \\
\hline $\mathrm{E}$ & {$[\mathrm{kJ} / \mathrm{mol}]$} & 260 \\
\hline
\end{tabular}

\subsection{Uniaxial tensile creep tests}

The creep tests were performed on a second generation FeCrAl alloy (designation C35MN) with a composition of Fe-13Cr-4.5Al-2Mo-1Nb-0.25Y-0.2Si and a grain size of $\sim 1 \mu \mathrm{m}$ [7]. Dog bone specimens with a gage section of $2 \times 2 \mathrm{~mm}$ were creep tested at $800^{\circ} \mathrm{C}$ with an applied stress of 20 and $26 \mathrm{MPa}$. The dead load creep machines were equipped with a radiation furnace and the temperature controlled within $\pm 2^{\circ} \mathrm{C}$ using two type $\mathrm{S}$ thermocouples attached to the specimen heads. High temperature rods clamped to the specimen grips and connected to two linear variable differential transformer (LVDT) were used to generate semi-quantitative creep curves.

\section{Results}

\subsection{Experimental results}

An example pressure and temperature profile during a burst sequence of a Zircaloy-4 tube is shown in Fig. 3. Initially, the system was stabilized at $300^{\circ} \mathrm{C}$ with continuous steam injection During the ramp-up, the tube temperature increased rapidly and resulted in a modest pressure increase of the small volume of gas at the pellet-cladding gap. The sudden drop in tube internal pressure marks the onset of cladding burst. The cladding continued to experience oxidation in steam until after the ramp-down to $800^{\circ} \mathrm{C}$, when it was water quenched.

The results from burst tests on Zircaloy-2, Zircaloy-4, 304SS, and $1^{\text {st }}$ generation FeCrAl alloys are summarized in Fig. 4. As consistent with convention [47], the results consist of burst temperature as a function of engineering hoop stress, Fig. 4(a). However, for the sake of clarity, the burst temperature as a function of rod internal pressure is also plotted, Fig. 4(b). Burst temperature can be easily deduced by noting the temperature at the point of pressure loss from 
the rod, as shown in Fig. 3. The engineering hoop stress is defined per Eq. (1), where the radius and thickness are those of as-fabricated cladding and the specified internal overpressure was the value at the moment of burst. Two empirical correlations for the onset of burst temperature as a function of hoop stress developed based on prior data on Zr-alloys [48, 49] and 304SS [46] are also shown in Figure 4 and show good agreement with the data. Given the same engineering hoop stress, the onset of burst for the $1^{\text {st }}$ Gen FeCrAl alloys examined in this study is $\sim 10 \%$ higher than for Zr-based alloys. Note that given neutronics considerations to meet cycle length requirements, a thinner FeCrAl cladding is needed when compared to Zr-based alloys [50]. Therefore, for the same rod internal pressure, the resulting hoop stress in the thin Fe-based cladding will be higher (Eq. (1)). As shown in Fig. 4(b), the FeCrAl claddings examined in this study show superior burst behavior at rod internal pressures below $4 \mathrm{MPa}$ and above that value they tend to behave similar to Zr-based claddings.

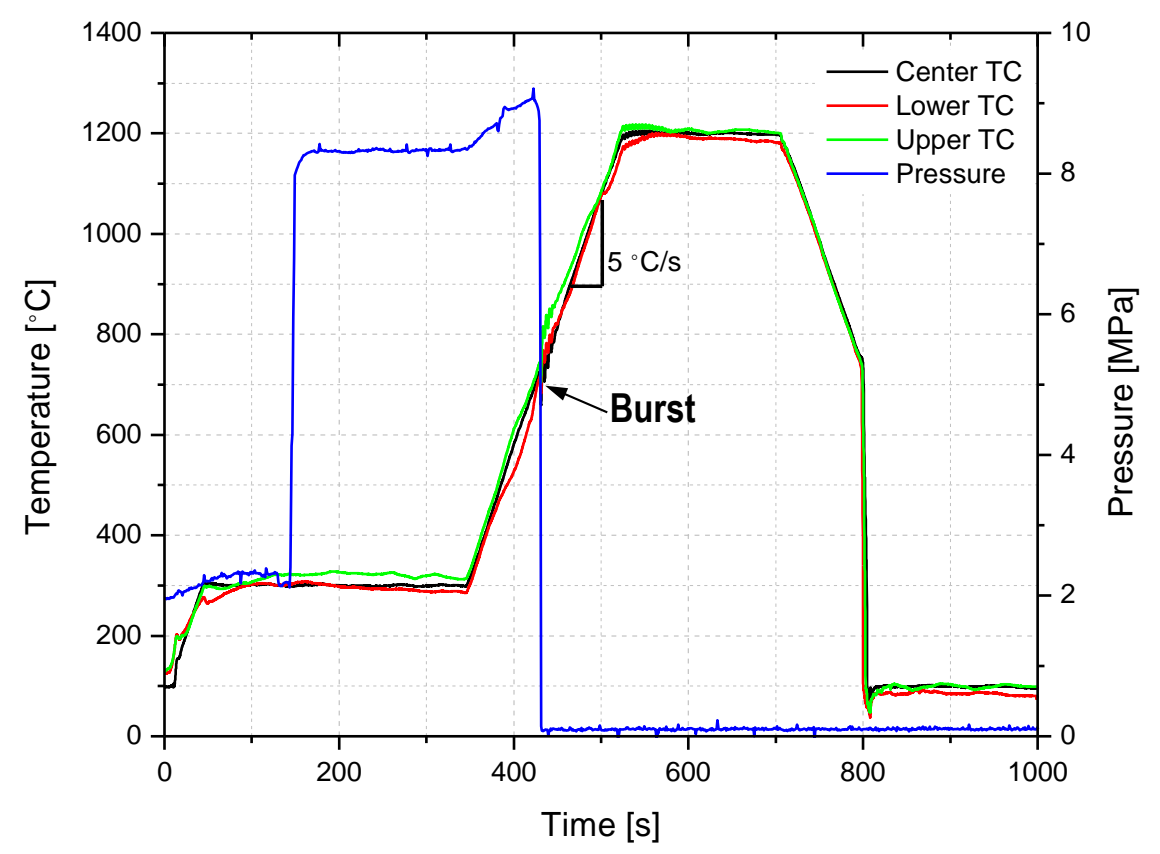

Figure 3. Continuously measured temperature and pressure evolution as a function of time for a Zircaloy4 rod during an integral LOCA test. 


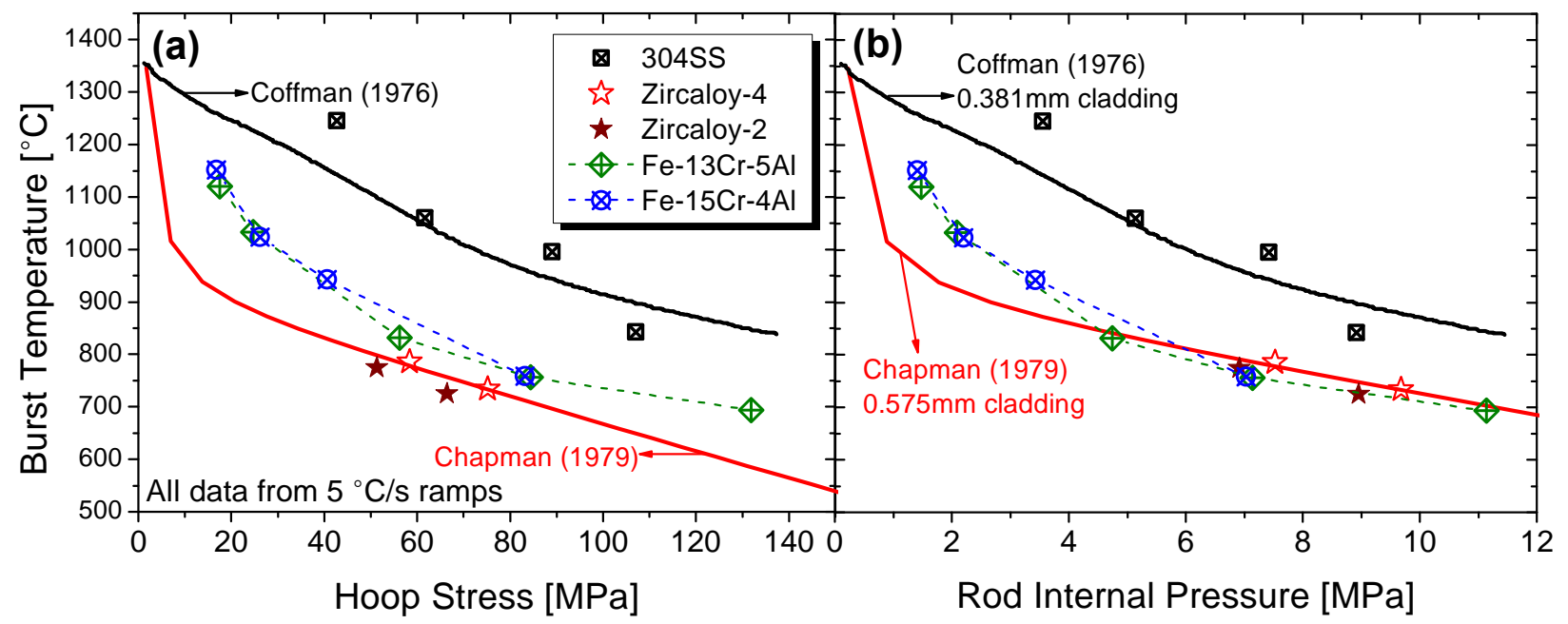

Figure 4. Burst temperature as a function of a) engineering hoop stress and b) rod internal pressure for various cladding materials examined in this study (scatter data) alongside empirical correlations from prior literature for Zr-alloys [49] and 304SS [46] (lines).

Fig. 5 shows a comparison between the diametrical strains of Zircaloy-2, 304SS, and $1^{\text {st }}$ Gen $\mathrm{FeCrAl}$ cladding material measured after burst for the entire cladding excluding the burst opening. The rod internal pressure in these cladding materials resulted in a hoop stress of $\sim 60$ Mpa at the onset of burst. However, the burst temperature varied between these different materials and Zircaloy-2 exhibited the largest diametrical strain after failure in the regions away from the burst opening. $1^{\text {st }}$ Gen FeCrAl cladding and 304SS exhibited significantly smaller strains in those regions, even though their burst temperatures were higher than the $\mathrm{Zr}$-based alloy. Note that the diameter of the remaining cladding in the region of burst opening was not measured in this study. The burst strain measured here for Zircaloy-2 and 304SS is in agreement with prior literature data, ref [8] and [39], respectively. However, Portier et al. [51] have observed brittle failure in 304SS without any ballooning during tests in an induction furnace and involving rapid increase in pressure at the test temperature. Note that upon changing their test procedure, by introducing a temperature stabilization period, their results proved consistent with the prior literature. It is important to note that at least for Zr-based alloys, the burst strain is a strong function of heating rate, since the heating rate changes the onset of burst temperature at any given pressure. This is the case since $\mathrm{Zr}$-based cladding experiences significant creep under these transients; this will be discussed in detail in the following subsection. 


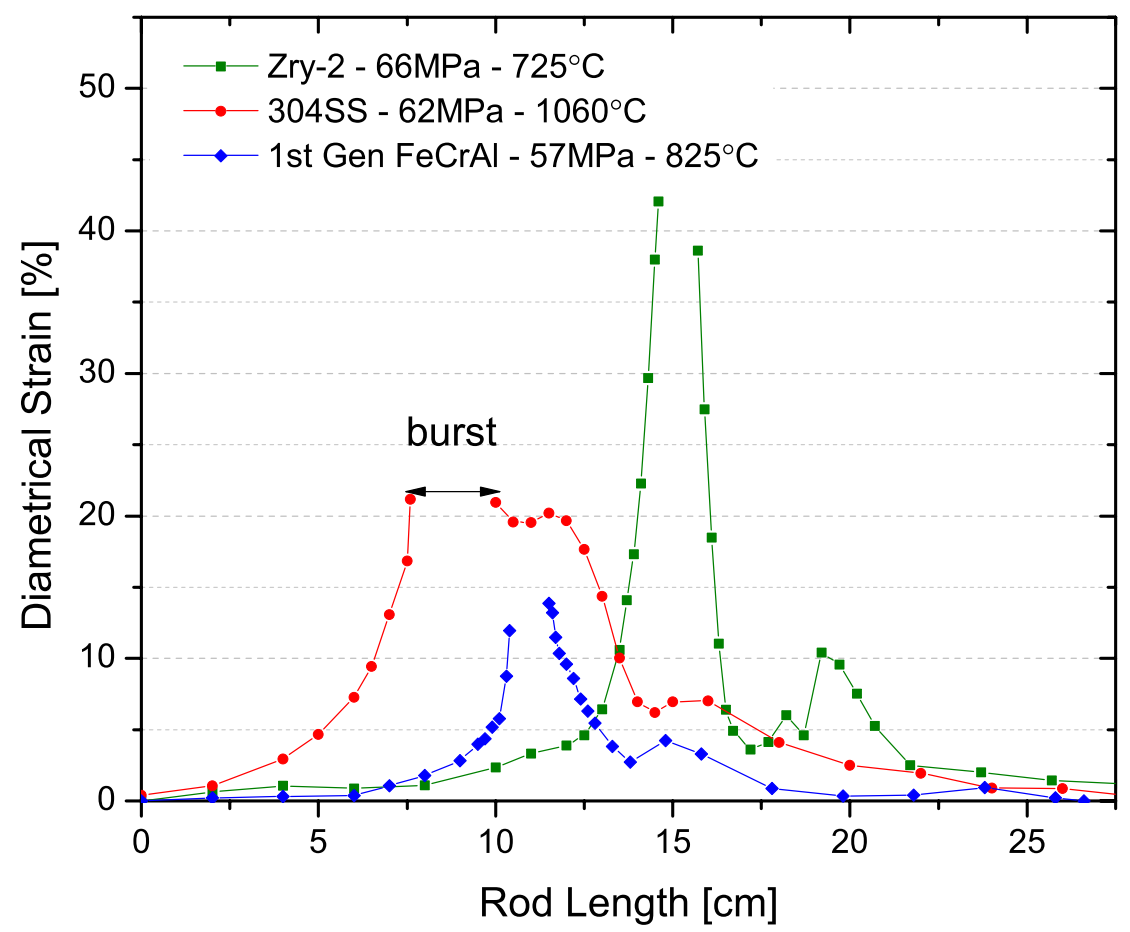

Figure 5. Post-burst measurement of diametrical strain for the various cladding materials across the cladding height and excluding the burst opening.

Fig. 6 shows superimposed light optical micrographs of the various cladding cross sections at the center of the burst, and at the extreme end of the rod, where the magnitude of diametrical strain was close to zero. Note that a significant reduction in wall thickness was apparent for the Zircaloy-4 cladding (Fig. 6a) along with a uniform ballooned shape at the burst center with a relatively small burst opening. In case of the Fe-based alloys (Fig. 6b,c), both 304SS and $1^{\text {st }}$ Gen $\mathrm{FeCrAl}$ alloys exhibited large burst openings and do not show signs of significant reduction in thickness. Post burst photographs of $1^{\text {st }} \mathrm{Gen} \mathrm{Fe}-13 \mathrm{Cr}-5 \mathrm{Al}$ burst at various temperatures are shown in Fig. 7. These images show that for larger internal stresses resulting from cladding overpressure, the corresponding burst temperatures are lower with a larger burst opening. For higher temperatures, the burst opening is much smaller, but the extent of ballooning in this $1^{\text {st }}$ Gen FeCrAl cladding was still minimal. These two figures potentially imply that the extent of ballooning was minimal prior to burst and the majority of deformation occurred once the onset of mechanical instability (essentially the ultimate tensile strength) had been reached and rapid plastic deformation had taken place locally at the burst opening.

Maintaining a coolable core geometry is an important requirement for any cladding, one aspect of which involves the possibility of flow blockage due to excessive ballooning of the cladding. Although for the Fe-based alloys large burst openings are observed, this does not necessarily result in flow blockage. In fact the most severe cases of blockage result from excessive ballooning with a small burst opening. As shown in Figs. 7 and 8, the large burst openings in Fe- 
based alloys may accommodate coolant flow past the rod. In any case, according to the results from the REBEKA tests [52], flow blockage up to $90 \%$ does not compromise coolability in an assembly.
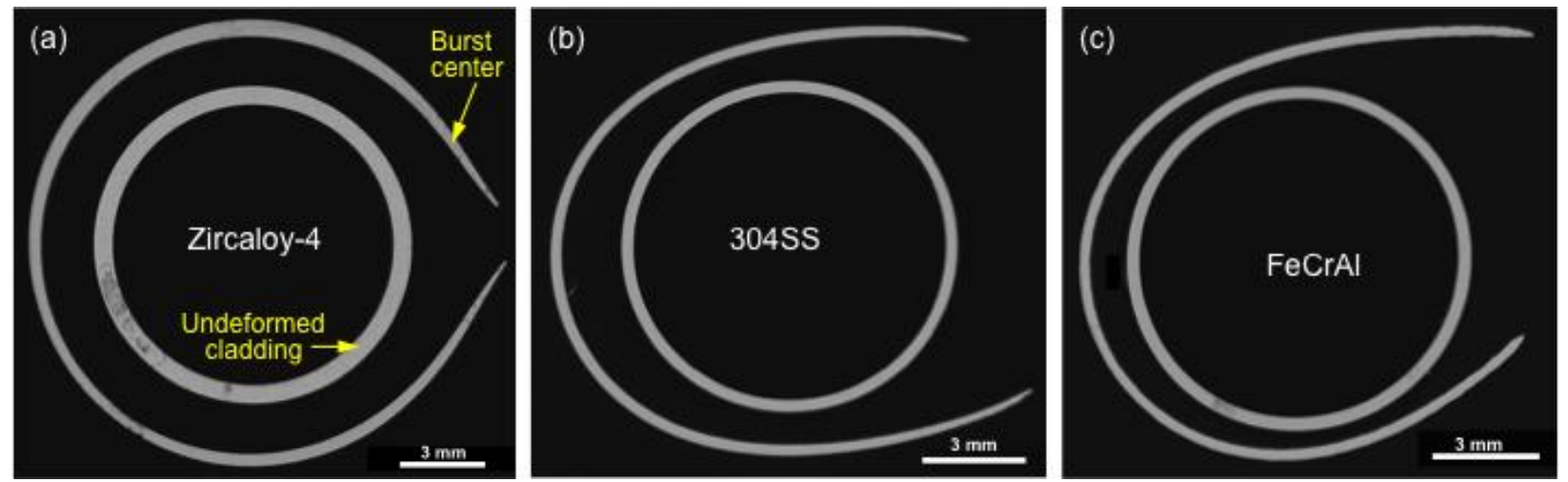

Figure 6. Light optical micrographs of the cladding cross-sections at the center of the burst and at the unreformed region at extreme end of the rod away from the heating zone.

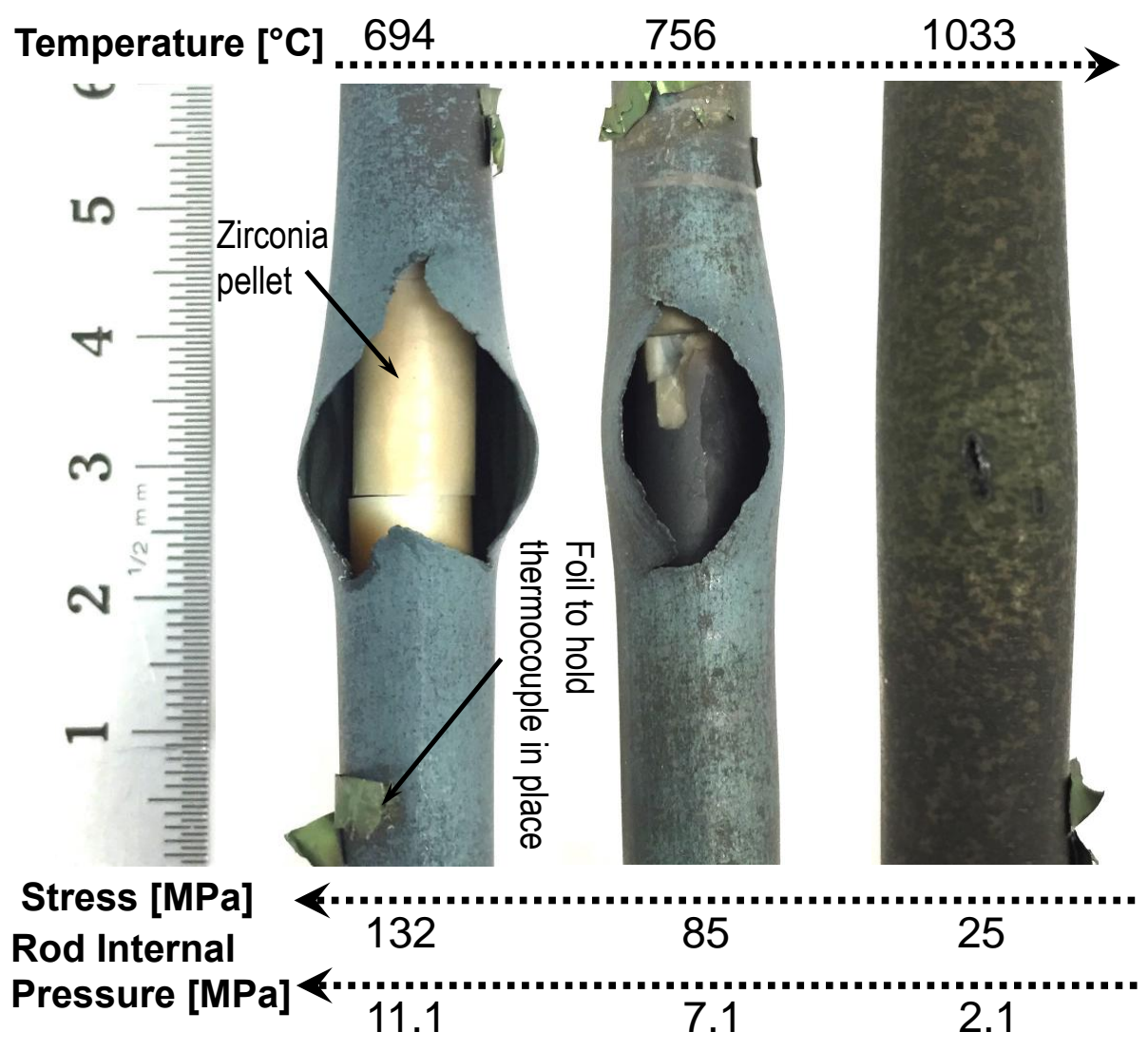

Figure 7. Post burst photographs of $\mathrm{Fe}-13 \mathrm{Cr}-5 \mathrm{Al}$ for three different burst conditions 
Finally, Fig. 8 shows SEM micrographs of the various cladding cross sections at the burst plane. Fig. 8a shows significant oxidation that has taken place after the LOCA sequence in Zircaloy-4 cladding. Note that both sides of the cladding have been oxidized, roughly to similar extents, indicating that almost the entirety of oxidation took place after the cladding experienced burst. Fig. 8b shows the higher magnification image of the oxidized outer diameter where the presence of the oxygen-stabilized $\alpha$-phase is clearly evident underneath the zirconia layer. Fig. 8c, similar to the case of Zircaloy, shows the presence of outer and inner oxide layers on the surface of 304SS cladding. At higher magnification in Fig 8d, the outer layer appears to be a relatively dense $\mathrm{FeO}_{\mathrm{x}}$ layer, while the inner layer appears to be an internal oxidation layer of spinel-type (Fe,Cr) oxide and metal. However, unlike Zircaloy-4 specimen, the 304SS substrate adjacent to the inner layer appears unaffected. This is expected since the solubility of oxygen is negligible in fcc or bec iron [53].

In contrast with the other two alloys, Fig. 8e shows the cross section of the FeCrAl cladding that has experienced negligible oxidation owing to a protective Al-rich oxide on the surface of the cladding (Fig. 8f). Note that the extent of oxidation in these images is important for determining the load-bearing capability and the ductility of the cladding in the post-quench state. However, it is not possible to determine the extent and therefore the impact of oxidation on the burst behavior of these materials during the transient test from these images which reflect the entire temperature history after burst including the $3 \mathrm{~min}$ hold at $1200^{\circ} \mathrm{C}$. A discussion on this topic is provided in section 5 .

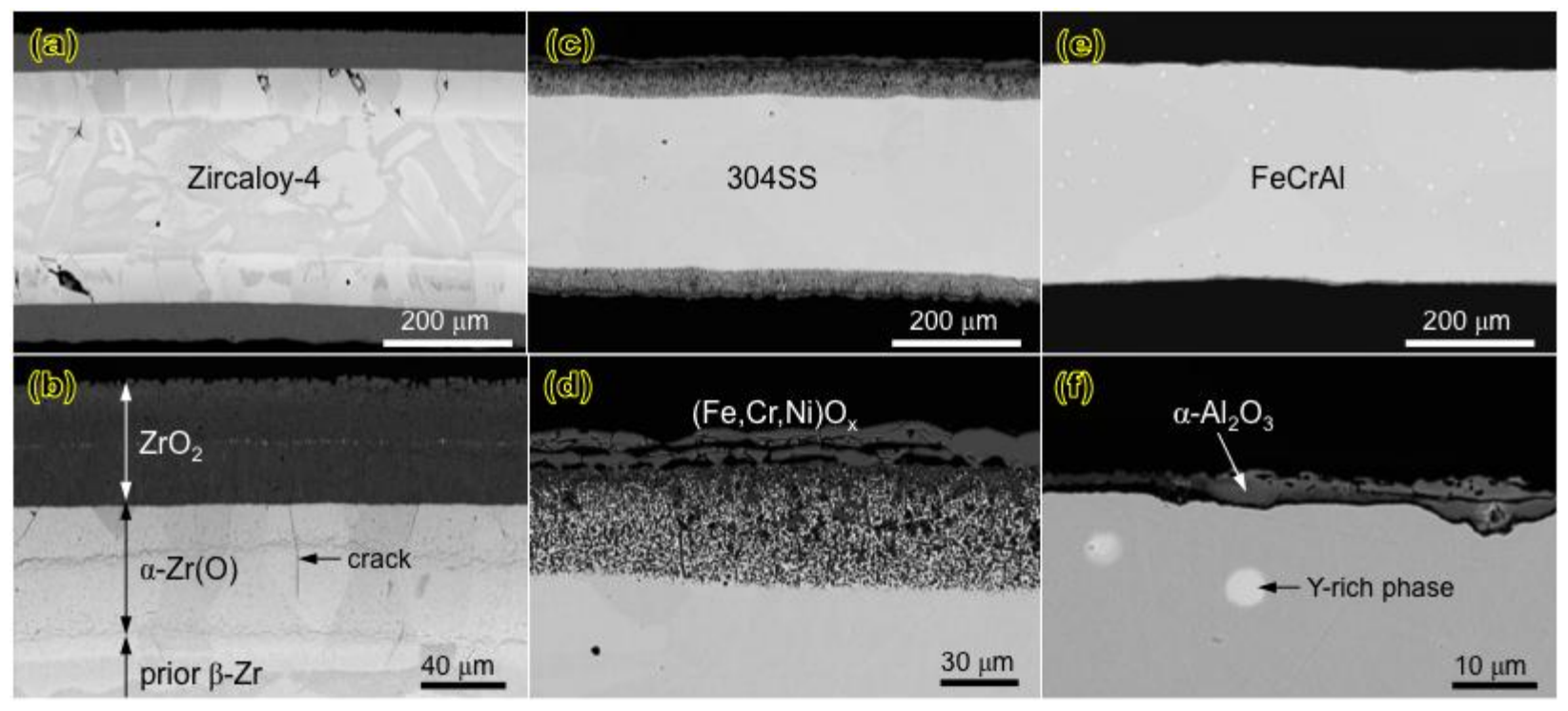

Figure 8. Backscattered election images of the various cladding cross-sections at the burst plane after the LOCA test sequence.

\subsection{Modeling results}

\subsubsection{Analysis of the experimental results}


One of the experiments from this study, a 304SS burst test, was selected and reproduced using the modeling framework discussed in section 3.2 to examine the predictability of the model. Table 4 provides a comparison between the modeling and experimental results. The specific burst criterion for the modeling case was the ultimate tensile strength (UTS) from [32]. The rod internal pressure and geometry (Table 1) were inputs to the modeling frameworks to then predict a burst temperature. Figure 9 illustrates the evolution in hoop stress and strain profiles for 304SS for the ramp conditions described in the previous sections. The calculated strain due to plastic and creep deformation was calculated as $22 \%$, which is in agreement with the $22 \%$ experimental strain shown in Figure 4. However, the computed 304SS case gives a burst stress of $112 \mathrm{Mpa}$ and a burst temperature of $882^{\circ} \mathrm{C}$. The predicted burst temperature was substantially lower than the experimentally determined value of $1060^{\circ} \mathrm{C}$.

Table 4. Comparison between the experimental and modeling results for one of the 304SS cladding burst tests.

\begin{tabular}{|c|c|c|l|l|c|}
\hline \multicolumn{2}{|c|}{ Experiment } & \multicolumn{3}{c|}{ Modeling } \\
\hline $\begin{array}{l}\text { Engineering Hoop } \\
\text { Stress at Burst [MPa] }\end{array}$ & $\begin{array}{c}\text { Burst } \\
\text { Temperature }\left[{ }^{\circ} \mathrm{C}\right]\end{array}$ & Strain & $\begin{array}{l}\text { Effective Hoop } \\
\text { Stress at Burst } \\
{[\mathrm{MPa}]}\end{array}$ & $\begin{array}{l}\text { Burst } \\
\text { Temperature }\left[{ }^{\circ} \mathrm{C}\right]\end{array}$ & Total strain \\
\hline 61.6 & 1060 & $22 \%$ & 112 & 882 & $22 \%$ \\
\hline
\end{tabular}

As discussed in more detail in the next subsection, creep was insignificant for 304SS. Therefore the burst behavior of this material is ultimately governed by the elastoplastic strain and UTS at high temperatures. The discrepancy in the predicted and actual burst temperature values for SS304 is therefore attributed to the conservative estimates for the mechanical properties of the alloy used in the computation; specifically low-strain-rate data from Gardner et al.. Figure 10 shows the variation in 304SS UTS with temperature from various references [32, 36, 37] along with the Coffman 304SS cladding burst criterion [46]. Also shown in the figure as scatter points, are the predicted onset of burst as a function of temperature using the model developed in this study. Note that all the UTS data are conservative compared to the Coffman burst criterion. Also, even though the model utilized the UTS data from Gardner et al., at low stresses the onset of burst was even lower. This is the case since higher temperatures under these conditions result in larger elastic and plastic strains that amplify the stress in the thin cladding. Note that, unlike the case for Zr-based alloys, creep does not contribute to the plastic strains that amplify the stress. This is explained in the next subsection.

Ultimately the model developed here fails to accurately predict the onset of burst in 304SS cladding since the material property data input into it are not appropriate to capture the behavior of cladding under these rapid LBLOCA transients. Therefore, focused studies to capture the 
appropriate material property data for Fe-based alloys, similar to what was carried out for $\mathrm{Zr}$ based alloys, are necessary to inform the model. 


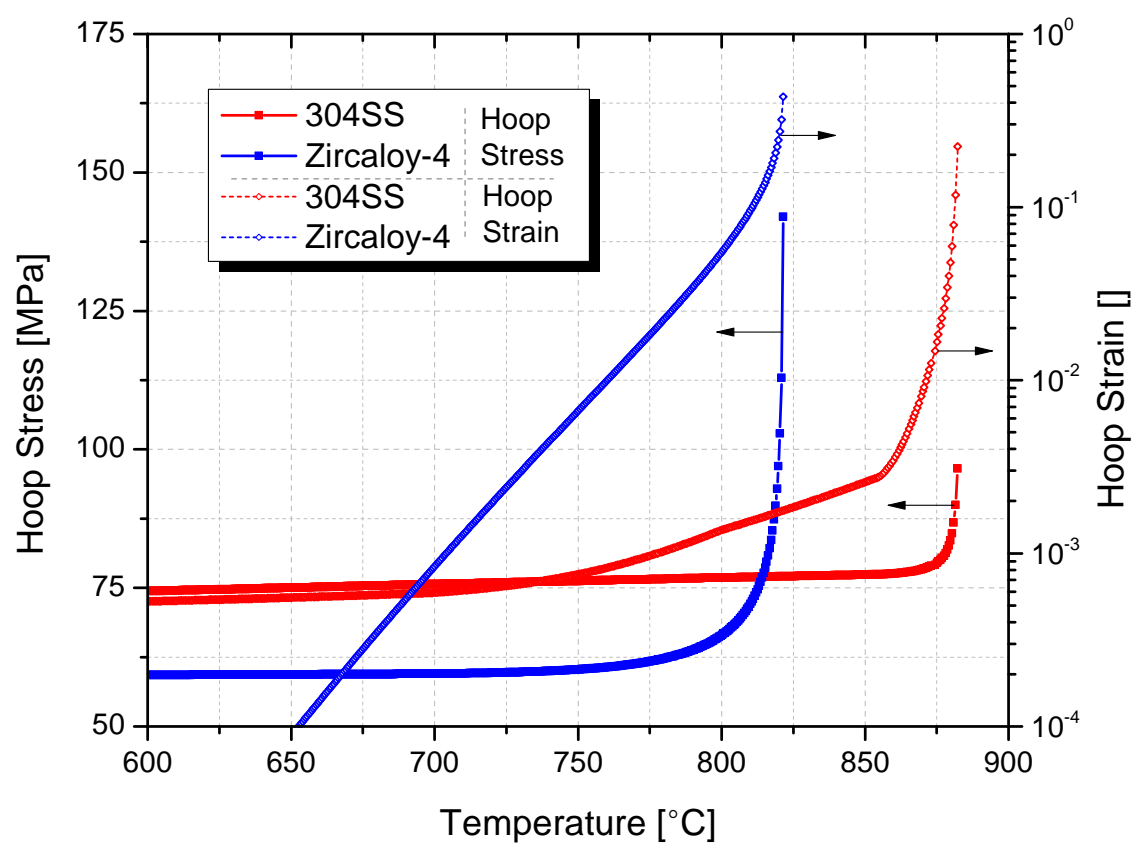

Figure 9. True hoop stress and hoop strain for Stainless Steel and Zircaloy-4 for computed burst cases.

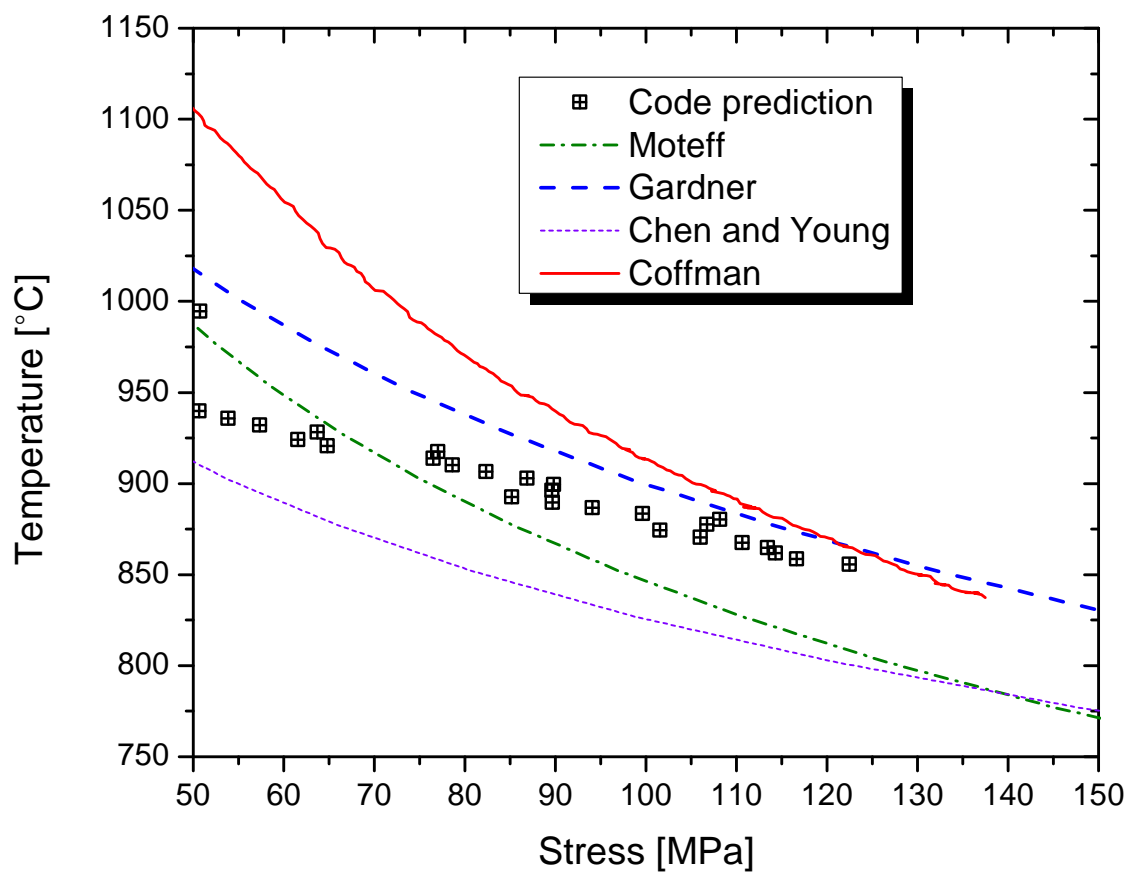

Figure 10. Comparison of various reported 304SS UTS and Coffman burst criterion. The predicted burst temperature as a function of engineering hoop stress using the model in this study is also shown as scatter points.

\subsubsection{Direct comparison of cladding behavior between $\mathrm{Zr}$ - and Fe-based alloys}

In this section, identical geometry and experimental conditions were assumed between the two cladding variants, Zircaloy-4 and 304SS, and the evolution of stress and strain in the cladding 
were examined. The model described in Sect. 3.2 was used to examine 304SS while the framework developed by Manngård and Massih [10] was used for the Zr-based cladding. The strain evolution on 304SS has been broken into each individual component, namely creep, elastic, and plastic contributions to the total strain. In this manner the most significant component and therefore mechanism for deformation could be identified. Note that for Zr-based alloys, creep strain dominated the deformation process and therefore it was the sole component taken into account [10].

The postulated conditions are as follows: $5 \mathrm{~K} / \mathrm{s}$ ramp rate with internal pressure in the tube of 6.9 Mpa (1000 psi) at the start of the test. The geometry of the cladding was that of $17 \times 17$ PWR fuel bundles, essentially what was noted for Zircaloy-4 in Table 1. Figure 11 shows the variation in true hoop stress and strain across the Zircaloy-4 and 304SS cladding materials. Note that among all the various strain components in $304 \mathrm{SS}$, creep strain was by far the smallest contributor, at least 7 orders of magnitude smaller than the rest. As the temperature increased, the elastic strain increased steadily until the yield stress was reached, and plastic deformation quickly became the dominant mechanism for cladding deformation and burst. Therefore any deformation due to cladding creep in 304SS can be ignored, while the elastoplastic deformation with respect to the experimental temperature history must be carefully evaluated for an accurate prediction of burst properties. This implies that in great contrast with Zr-based alloys, creep in 304SS did not contribute to stress amplification during the course of the test per Eq. (2). This implies that necking and ductile fracture due to loading of the cladding is the main mechanism for 304SS cladding failure.

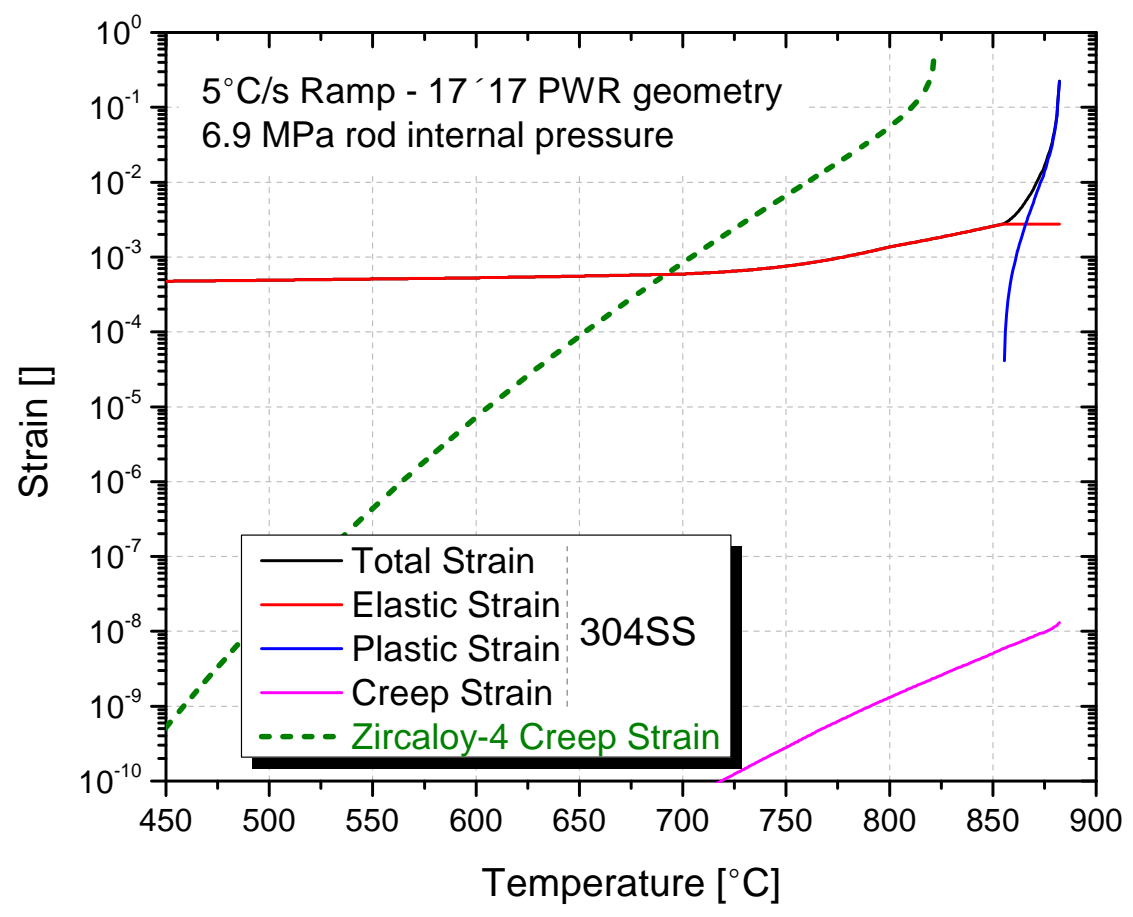


Figure 11. Strain profile across the Zircaloy- 4 and 304 SS cladding materials with $17 \times 17$ PWR geometry during a postulated ramp test. Internal pressure at the start of the $5 \mathrm{~K} / \mathrm{s}$ temperature ramp is $6.9 \mathrm{Mpa}$.

\subsection{Creep rate comparison}

Fig. 12 shows the deformation as a function of time for the $\mathrm{C} 35 \mathrm{MN} \mathrm{FeCrAl}$ alloy at $800^{\circ} \mathrm{C}$. The steady state creep rate was extracted from each test is noted. Fig. 13 is a contour plot that provides a side-by-side comparison of steady-state creep strain rate for Zircaloy-4 and 304SS $[33,54]$. Also included in that plot as scatter points, are the two steady state creep rates determined in Figure 9 for C35MN. The figure clearly shows that 304SS is significantly more creep-resistant than Zircaloy-4. The ferritic FeCrAl alloy, although much more susceptible to creep when compared with austenitic 304SS, exhibited a steady state creep rate roughly two orders of magnitude smaller than Zircaloy-4. Note that as shown in the figure, the creep rate of Zircaloy-4 increased further once the temperature onset of the phase transformation $(\alpha \rightarrow \beta)$ was passed. This implies that the conclusions drawn for 304SS with respect to governing phenomena for cladding burst are likely to also be applicable for FeCrAl cladding tubes. Specifically, this means that creep will not play an important role in amplifying the stress in the cladding as a result of plastic strain, and the burst will be largely the effect of stress surpassing the point of instability in the engineering stress strain curve at any given temperature.

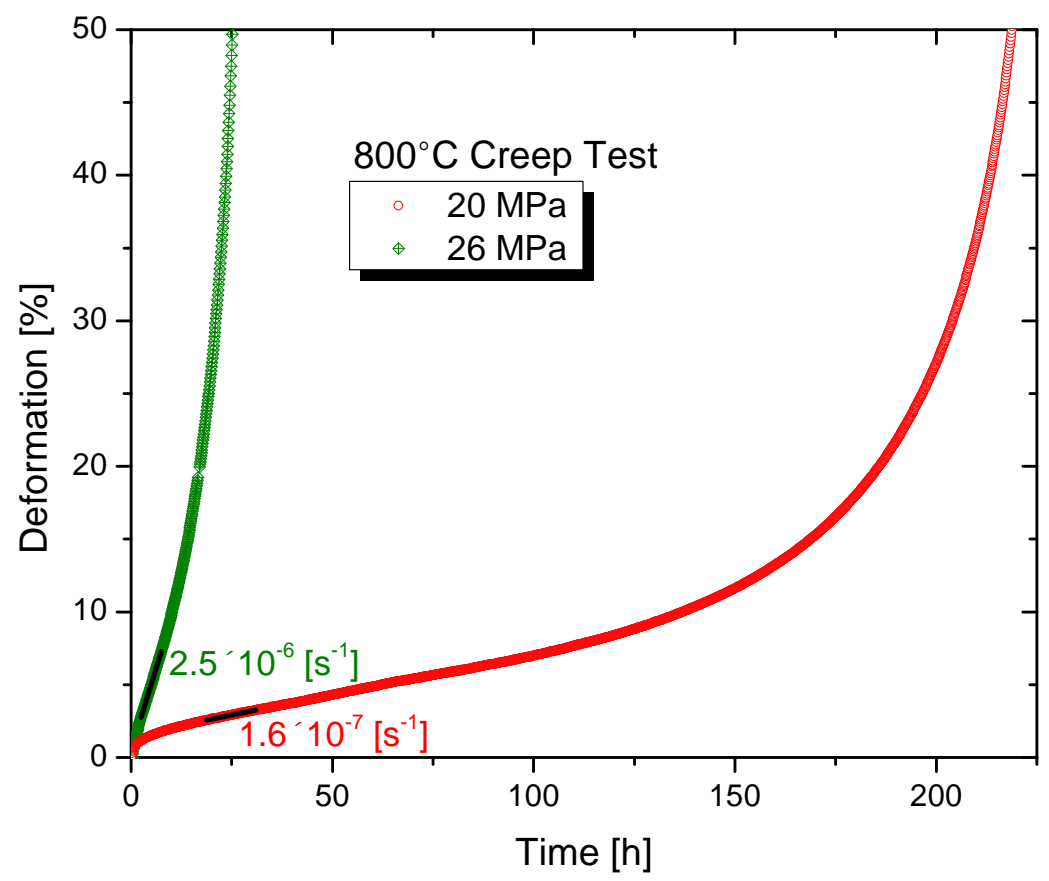

Figure 12. Deformation as a function of time for $\mathrm{C} 35 \mathrm{MN} \mathrm{FeCrAl}$ alloy at 20 and $26 \mathrm{Mpa}$ and $800^{\circ} \mathrm{C}$. 


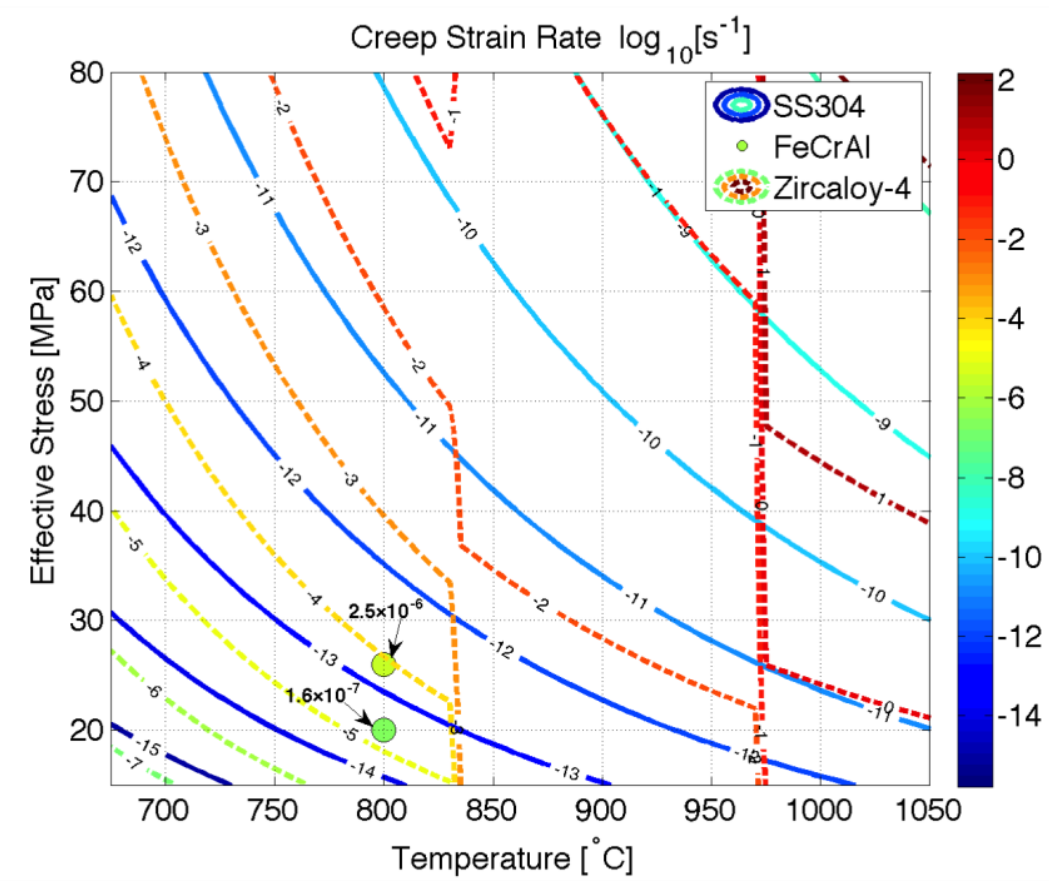

Figure 13. Contour plot of steady-state creep strain rate for Zircaloy-4 and 304SS [33, 54] as a function of stress and temperature. Steady state creep rate of C35MN FeCrAl alloy are also shown in the figure as scatter points.

\section{Discussion}

\subsection{The effect of oxidation on the burst behavior of the cladding}

The effect of steam oxidation on the burst behavior of the various cladding materials is largely due to conversion of a fraction of the load-bearing metal on the outer surface of the cladding to an oxide layer that is incapable of withstanding the tensile loads. Other considerations are also important for Zr-based alloys as discussed in section 2. Figure 14 shows the thickness of the oxide forming on the surface of Zr-based alloys, 304SS, and FeCrAl materials during a typical LOCA ramp profile (Figure 2). The parabolic oxidation rate constants for Zr-based alloys and $\mathrm{FeCrAl}$ alloys have been extracted from Refs [13] and [55], respectively.

The calculated oxide thickness for the various cladding materials in Figure 14 is in adequate agreement with the experimental results in Figure 5. The current calculation does not take into account the oxygen dissolution in the $\alpha-\mathrm{Zr}(\mathrm{O})$ phase and therefore overestimates the $\mathrm{ZrO}_{2}$ layer thickness. The oxide layer thickness for 304SS in Figure 8 falls in between the predictions based on the two different correlations in the literature noted in Table 2. Note that almost no oxidation is predicted for $\mathrm{FeCrAl}$ alloys, consistent with Figure 8.

The other important takeaway from Figure 14 is that the oxide layer thickness in the temperature range most pertinent for burst processes $\left(700-1000^{\circ} \mathrm{C}\right)$ is largest for $\mathrm{Zr}$-based alloys. Therefore, 
even for austenitic steels with relatively poor oxidation resistance in high-temperature steam, oxidation is not a major factor affecting the burst process.

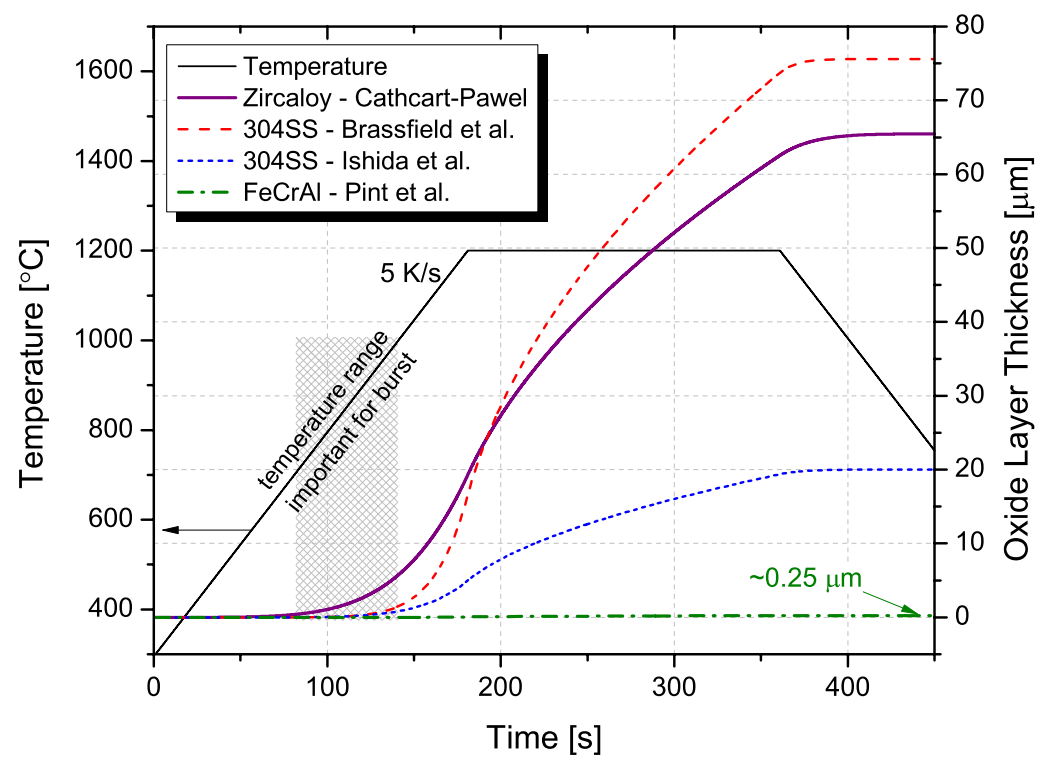

Figure 14. Oxide layer thickness as a function of time during a LOCA temperature excursion in steam with $5 \mathrm{~K} / \mathrm{s}$ ramp for various cladding materials.

\section{Summary}

Cladding burst tests were carried out at ORNL's Severe Accident Test Station to access the burst behavior of austenitic and ferritic Fe-based alloys in comparison to reference Zircaloy-2 and Zircaloy-4 claddings. From the burst results, engineering stress vs. burst temperature curves were developed for the various alloys that are consistent with previous correlations found in the literature. The data show that at the same engineering hoop stress, the examined $1^{\text {st }} \mathrm{Gen} \mathrm{FeCrAl}$ alloys demonstrated $\sim 10 \%$ higher temperature (and thus time to burst) at the onset of burst in comparison to the referenced $\mathrm{Zr}$-based alloys. This higher resistance to burst is consistent in both compositions of $1^{\text {st }}$ Gen FeCrAl claddings evaluated, illustrating that minor compositional changes between alloys did not affect the burst behavior of these ATF cladding materials.

Microscopic examination of burst openings for the compared materials were undertaken, and both $1^{\text {st }}$ Gen FeCrAl cladding and 304SS exhibited significantly smaller diametrical strains in comparison with Zr-based alloys even though the burst temperatures were higher for the Febased alloys. This lack of strain, coupled with the notably larger burst openings for the austenitic and ferritic Fe-based alloys implies that the burst criterion for these alloys is governed by the onset of thermomechanical instability and is not similar to Zr-based alloys. 
Scanning electron micrographs of cladding burst openings, coupled with detailed analyses of oxidation kinetics for Zircaloy-4, 304SS, and $1^{\text {st }} \mathrm{Gen} \mathrm{FeCrAl}$, show that in the temperature range of LOCA scenarios $\left(700^{\circ}-1000^{\circ} \mathrm{C}\right) \mathrm{Fe}$-based alloys exhibited substantially slower oxidation kinetics resulting in a negligible reduction in load bearing capacity for these cladding materials in comparison with reference $\mathrm{Zr}$-based alloys. This lack of oxidation also will decrease hydrogen and heat generation during these accident scenarios.

Modeling results undertaken for 304SS demonstrate that for austenitic stainless steels, in agreement with the experimental burst data presented, the influence of creep was negligible in determining the onset of burst. Though the predicted burst temperature was lower than experimental results for this model, the mechanisms of deformation were dominated by the timeindependent thermomechanical properties of the alloy and are highly dependent on the material property database used. This argument is strengthened by the model's ability to successfully capture the diametrical strain at the onset of burst, which is dominated by the plastic deformation at the onset of thermomechanical instability. Thus, in comparison to $\mathrm{Zr}$-based alloys whose failure mechanisms are strongly influenced by time and temperature dependent creep and oxidation, Fe-based alloys including the $1^{\text {st }} \mathrm{Gen} \mathrm{FeCrAl}$ alloys of interest are not dominated by thermal creep. This argument is strengthened by the two $800^{\circ} \mathrm{C}$ creep experiments, that illustrate that for higher strength $2^{\text {nd }} \mathrm{Gen}$. FeCrAl alloys the steady state creep rate was roughly two orders of magnitude smaller than the creep rate of Zircaloy-4.

\section{Acknowledgments}

The aid and technical insight of Mike Howell, Yong Yan, Yuri Kato, and Lance Snead at ORNL is gratefully acknowledged. Stuart Maloy at Los Alamos National Laboratory organized FeCrAl tube production at Century Tubes Inc., San Diego, CA. Maxim Gussev, Yukinori Yamamoto, and Byoungkoo Kim provided useful comments on the manuscript. The work presented in this paper was supported by the Advanced Fuels Campaign of the Fuel Cycle R\&D program in the Office of Nuclear Energy, US Department of Energy.

\section{References}

[1] K. A. Terrani, S. J. Zinkle, and L. L. Snead, "Advanced oxidation-resistant iron-based alloys for LWR fuel cladding," Journal of Nuclear Materials, vol. 448, pp. 420-435, 2014.

[2] S. J. Zinkle, K. A. Terrani, J. C. Gehin, L. J. Ott, and L. L. Snead, "Accident tolerant fuels for LWRs: A perspective," Journal of Nuclear Materials, vol. 448, pp. 374-379, 2014.

[3] M. T. Farmer, L. Leibowitz, K. A. Terrani, and K. R. Robb, "Scoping assessments of ATF impact on latestage accident progression including molten core-concrete interaction," Journal of Nuclear Materials, vol. 448, pp. 534-540, 2014.

[4] L. J. Ott, K. R. Robb, and D. Wang, "Preliminary assessment of accident-tolerant fuels on LWR performance during normal operation and under DB and BDB accident conditions," Journal of Nuclear Materials, vol. 448, pp. 520-533, 2014.

[5] A. Strasser, J. Santucci, K. Lindquist, W. Yario, G. Stern, L. Goldstein, et al., "An Evaluation of Stainless Steel Cladding for Use in Current Design LWRs, NP-2642," Electric Power Research Institute, Palo Alto, CA1982. 
[6] D. H. Locke, "Review of experience with water reactor fuels 1968-1973," Nuclear Engineering and Design, vol. 33, pp. 94-124, 1975.

[7] K. G. Field, X. Hu, K. C. Littrell, Y. Yamamoto, and L. L. Snead, "Radiation tolerance of neutronirradiated model Fe-Cr-Al alloys," Journal of Nuclear Materials, vol. 465, pp. 746-755, 2015.

[8] F. Erbacher, H. Neitzel, H. Rosinger, H. Schmidt, and K. Wiehr, "Burst criterion of Zircaloy fuel claddings in a loss-of-coolant accident," in Zirconium in the Nuclear Industry: Fifth Conference, volume ASTM STP, 1982, p. 271.

[9] M. Bocek, "Creep rupture at monotonous stress and temperature ramp loading II. Application to Zircaloy," Journal of Nuclear Materials, vol. 82, pp. 339-346, 1979.

[10] T. Manngård and A. R. Massih, "Modelling and Simulation of Reactor Fuel Cladding under Loss-ofCoolant Accident Conditions," Journal of NUCLEAR SCIENCE and TECHNOLOGY, vol. 48, pp. 39-49, 2011.

[11] T. Forgeron, J. Brachet, F. Barcelo, A. Castaing, J. Hivroz, J. Mardon, et al., "Experiment and modeling of advanced fuel rod cladding behavior under LOCA conditions: Alpha-beta phase transformation kinetics and EDGAR methodology," ASTM SPECIAL TECHNICAL PUBLICATION, vol. 1354, pp. 256-278, 2000.

[12] A. R. Massih, "An evaluation of high-temperature creep of zirconium alloys: data versus models, SSM 2014:20 " Swedish Radiation Safety Authority 2014.

[13] J. V. Cathcart, R. E. Pawel, R. A. McKee, R. E. Druschel, G. J. Yurek, J. J. Campbell, et al., "Zirconium metal-water oxidation kinetics, IV: reaction rate studies, ORNL/NUREG-17," Oak Ridge National Laboratory 1977.

[14] M. Billone, Y. Yan, T. Burtseva, and R. Daum, "Cladding Embrittlement During Postulated Loss-ofCoolant Accidents, NUREG/CR-6967," U.S. NRC, Office of Nuclear Regulatory Research2008.

[15] D. Kaddour, S. Frechinet, A.-F. Gourgues, J. Brachet, L. Portier, and A. Pineau, "Experimental determination of creep properties of zirconium alloys together with phase transformation," Scripta materialia, vol. 51, pp. 515-519, 2004.

[16] H. Sell and E. Ortlieb, "Effects of alpha-beta transformation on high temperature (LOCA) creep behavior of Zr-alloys," in Zirconium in the nuclear industry, ed, 2002.

[17] J. C. Brachet, C. Toffolon-Masclet, D. Hamon, T. Guilbert, G. Trego, J. Jourdan, et al., "Oxygen, Hydrogen and Main Alloying Chemical Elements Partitioning Upon Alpha $\longrightarrow$ Beta Phase Transformation in Zirconium Alloys," Solid State Phenomena, vol. 172, pp. 753-759, 2011.

[18] J.-C. Brachet, V. Vandenberghe-Maillot, L. Portier, D. Gilbon, A. Lesbros, N. Waeckel, et al., "Hydrogen Content, Preoxidation, and Cooling Scenario Effects on Post-Quench Microstructure and Mechanical Properties of Zircaloy-4 and M5 Alloys in LOCA Conditions," Journal of ASTM International, vol. 5, 2008.

[19] J.-C. Brachet, L. Portier, T. Forgeron, J. Hivroz, D. Hamon, T. Guilbert, et al., "Influence of Hydrogen Content on the Phase Transformation Temperatures and on the Thermal-Mechanical Behavior of Zy-4, M4 ( $\mathrm{ZrSnFeV})$, and M5 (ZrNbO) Alloys During the First Phase of LOCA Transient," ASTM International, West Conshohocken, PA2002.

[20] D. Kaddour, A.-F. Gourgues-Lorenzon, J.-C. Brachet, L. Portier, and A. Pineau, "Microstructural influence on high temperature creep flow of $\mathrm{Zr}-1 \% \mathrm{NbO}$ alloy in near- $\alpha,(\alpha+\beta)$, and $\beta$ temperature ranges in a high vacuum environment," Journal of Nuclear Materials, vol. 408, pp. 116-124, 2011.

[21] M. Moalem and D. R. Olander, "Oxidation of Zircaloy by steam," Journal of Nuclear Materials, vol. 182, pp. 170-194, 1991.

[22] M. Steinbrück, N. Vér, and M. Große, "Oxidation of Advanced Zirconium Cladding Alloys in Steam at Temperatures in the Range of 600-1200 ${ }^{\circ}$ C," Oxidation of metals, vol. 76, pp. 215-232, 2011.

[23] C. Corvalán-Moya, C. Desgranges, C. Toffolon-Masclet, C. Servant, and J. Brachet, "Numerical modeling of oxygen diffusion in the wall thickness of Low-Tin Zircaloy-4 fuel cladding tube during high temperature (1100-1250 C) steam oxidation," Journal of Nuclear Materials, vol. 400, pp. 196-204, 2010.

[24] J. Abriata, J. Garces, and R. Versaci, "The O- Zr (Oxygen-Zirconium) system," Bulletin of Alloy Phase Diagrams, vol. 7, pp. 116-124, 1986.

[25] C. Toffolon-Masclet, C. Desgranges, C. Corvalan-Moya, and J.-C. Brachet, "Simulation of the $\beta \rightarrow \alpha(O)$ phase transformation due to oxygen diffusion during high temperature oxidation of zirconium alloys," Solid State Phenomena, vol. 172-174, pp. 652-657, 2011.

[26] C. Grandjean and G. Hache, "A state of the art review of past programs devoted to fuel behaviour under LOCA conditions - part 3; cladding oxidation, resistance to quench and post quench loads,"

IRSN/DPAM/SEMCA 2008-093, http://net-science. irsn. org2008. 
[27] C. Grandjean, "A state of the art review of past programs devoted to fuel behaviour under LOCA conditions-part 2: impact of clad swelling upon assembly cooling," IRSN/DPAM/SEMCA 2006-183, http://net-science. irsn. org2006.

[28] C. Grandjean, "A State-of-the-Art Review of Past Programs Devoted to Fuel Behavior Under LOCA Conditions. Part One: Clad Swelling and Rupture. Assembly Flow Blockage," IRSN Technical Report SEMCA-2005-3132005.

[29] G. Repetto, F. Jacq, F. Barré, F. Lamare, and J. Ricaud, "DRACCAR, a new 3D thermal mechanical computer code to simulate LOCA transients on Nuclear Power Plants," in Proceedings of the International Congress on Advances in Nuclear Power Plants (ICAPP'09), 2009.

[30] B. A. Pint and K. A. Terrani, "Severe Accident Test Station (SATS) Activity Report, ORNL/LTR2015/217," Oak Ridge National Laboratory2015.

[31] Y. Yamamoto, B. A. Pint, K. A. Terrani, K. G. Field, and L. L. Snead, "Letter report documenting identifying billets and alloys fabricated for distribution to program, FY13 FCRD milestone report, M3FT13OR0202291, ORNL/LTR-2013/322," 2013.

[32] L. Gardner, A. Insausti, K. Ng, and M. Ashraf, "Elevated temperature material properties of stainless steel alloys," Journal of Constructional Steel Research, vol. 66, pp. 634-647, 2010.

[33] F. V. Tahami, A. H. Daei-Sorkhabi, and F. R. Biglari, "Creep constitutive equations for cold-drawn 304L stainless steel," Materials Science and Engineering: A, vol. 527, pp. 4993-4999, 2010.

[34] S. Holdsworth, M. Askins, A. Baker, E. Gariboldi, S. Holmström, A. Klenk, et al., "Factors influencing creep model equation selection," International Journal of Pressure Vessels and Piping, vol. 85, pp. 80-88, 2008.

[35] K. Sawada, M. Tabuchi, and K. Kimura, "Analysis of long-term creep curves by constitutive equations," Materials Science and Engineering: A, vol. 510, pp. 190-194, 2009.

[36] J. Chen and B. Young, "Stress-strain curves for stainless steel at elevated temperatures," Engineering Structures, vol. 28, pp. 229-239, 2006.

[37] J. Moteff, R. Bhargava, and W. McCullough, "Correlation of the hot-hardness with the tensile strength of 304 stainless steel to temperatures of 1200 C," Metallurgical transactions A, vol. 6, pp. 1101-1104, 1975.

[38] S. Chavez, G. Korth, D. Harper, and T. Walker, "High-temperature tensile and creep data for Inconel 600, 304 stainless steel and SA106B carbon steel," Nuclear engineering and design, vol. 148, pp. 351-363, 1994.

[39] H. C. Brassfield, J. F. White, L. Sjodahl, and J. T. Bittel, "Recommended Property and Reaction Kinetics Data for Use in Evaluating a Light-Water-Cooled Reactor Loss of Coolant Incident Involving Zircaloy-4 or 304SS Clad UO2, GEMP-482," General Electric Co.Apr 19681968.

[40] R. Hill, "A theory of the yielding and plastic flow of anisotropic metals," Proceedings of the Royal Society of London. Series A. Mathematical and Physical Sciences, vol. 193, pp. 281-297, 1948.

[41] H. Rosinger, "A model to predict the failure of Zircaloy-4 fuel sheathing during postulated LOCA conditions," Journal of Nuclear Materials, vol. 120, pp. 41-54, 1984.

[42] J. Matthews, "The effect of anisotropy on the ballooning of Zircaloy cladding," Nuclear engineering and design, vol. 77, pp. 87-95, 1984.

[43] T. Ishida, Y. Harayama, and S. Yaguchi, "Oxidation of 304 Stainless Steel in High-Temperature Steam," Journal of Nuclear Materials, vol. 140, pp. 74-84, 1986.

[44] K. Rao, Y. Prasad, and E. B. Hawbolt, "Hot deformation studies on a low-carbon steel: part 2-an algorithm for the flow stress determination under varying process conditions," Journal of materials processing technology, vol. 56, pp. 908-917, 1996.

[45] K. Rao, Y. Prasad, and E. B. Hawbolt, "Hot deformation studies on a low-carbon steel: Part 1-flow curves and the constitutive relationship," Journal of materials processing technology, vol. 56, pp. 897-907, 1996.

[46] F. D. Coffman, "LOCA Temperature Criterion for Stainless Steel Clad Fuel, NUREG-0065," 1976.

[47] D. Powers and R. Meyer, "Cladding swelling and rupture models for LOCA analysis, NUREG-0630," U. S. Nuclear Regulatory Commission 1980.

[48] R. Chapman, J. Crowley, A. Longest, and G. Hofmann, "Zirconium cladding deformation in a steam environment with transient heating," in Zirconium in the Nuclear Industry (Fourth conference), ASTM STP, 1979, pp. 393-408.

[49] R. H. Chapman, "MultirodBurstTest Program Proqress Report for April-June, 1979, USNRC Report NUREG/CR-1023, November, 1979," Oak Ridge National Laboratory, 1979. 
[50] N. M. George, K. Terrani, J. Powers, A. Worrall, and I. Maldonado, "Neutronic analysis of candidate accident-tolerant cladding concepts in pressurized water reactors," Annals of Nuclear Energy, vol. 75, pp. 703-712, 2015.

[51] L. Portier, J. Brachet, V. Vandenberghe, T. Guilbert, V. Lezaud-Chaillioux, C. Bernard, et al., "Creeprupture, steam oxidation and recovery behaviours upon dynamic transients up to $1300 \mathrm{C}$ of cold-worked 304 stainless steel tubes dedicated to nuclear core fuel cladding," presented at the Proceedings of Fontevraud 7, paper No A027, Avignon, France, 2010.

[52] F. J. Erbacher and S. Leistikow, A review of Zircaloy fuel cladding behavior in a loss-of-coolant accident: Kernforschungszentrum Karlsruhe, 1985.

[53] B. Sundman, "An assessment of the Fe-O system," Journal of phase equilibria, vol. 12, pp. 127-140, 1991.

[54] H. Rosinger, P. Bera, and W. Clendening, "Steady-state creep of Zircaloy-4 fuel cladding from 940 to 1873 K," Journal of Nuclear Materials, vol. 82, pp. 286-297, 1979.

[55] B. A. Pint, K. A. Terrani, Y. Yamamoto, and L. L. Snead, "Material Selection for Accident Tolerant Fuel Cladding," Metallurgical and Materials Transactions E, 2014. 